RUNNING HEAD: Underestimating our unethical influence

\title{
Underestimating Our Influence Over Others' Unethical Behavior and Decisions
}

Vanessa K. Bohns, M. Mahdi Roghanziad \& Amy Z. Xu

University of Waterloo, Waterloo, Ontario, Canada

Published in Personality and Social Psychology Bulletin

Send correspondence to:

\author{
Vanessa K. Bohns \\ Department of Management Sciences \\ University of Waterloo \\ 200 University Avenue West \\ Waterloo, Ontario, Canada N2L 3G1 \\ Canada \\ vbohns@uwaterloo.ca
}




\begin{abstract}
We examined the psychology of "instigators," i.e., people who surround an unethical act and influence the wrongdoer (the "actor") without directly committing the act themselves. In four studies, we found that instigators of unethical acts underestimated their influence over actors. In Studies 1 and 2, university students enlisted other students to commit a "white lie" (Study 1) or commit a small act of vandalism (Study 2) after making predictions about how easy it would be to get their fellow students to do so. In Studies 3 and 4, online samples of participants responded to hypothetical vignettes, e.g., about buying children alcohol, and taking office supplies home for personal use. In all 4 studies, instigators failed to recognize the social pressure they levied on actors through simple unethical suggestions, i.e., the discomfort actors would experience by making a decision that was inconsistent with the instigator's suggestion.
\end{abstract}




\section{Underestimating Our Influence Over Others' Unethical Behavior and Decisions}

Moody's had just graded a pool of securities underwritten by Countrywide Financial, the nation's largest mortgage lender. But Countrywide complained that the assessment was too tough. The next day, Moody's changed its rating, even though no new and significant information had come to light. -Morgenson, 2008, New York Times

Unethical acts are frequently conducted at the behest of someone else. Other people can successfully goad us into doing things that make us uncomfortable because it is even more uncomfortable to say "no" (Sabini, Siepman, \& Stein, 2001). In the example described above, the Moody's representative felt pressured to consider, and ultimately honor, Countrywide's request to alter the ratings, the consequences of which were devastating to the housing market in 2007. Although the ultimate decision to finagle Countrywide's credit ratings was Moody's, the Countrywide representative instigated the Moody's representative's unethical behavior.

The current research contrasts the perspective of "actors," i.e., individuals who ultimately engage in unethical behaviors, to "instigators," i.e., individuals who influence or incite unethical behaviors. Specifically, we examine the question of whether instigators recognize the awkward position they put actors in when they make an unethical request. Drawing from previous research on help-seekers' estimates of the likelihood that potential helpers will comply with their prosocial requests (Flynn and Lake [Bohns], 2008), we hypothesize that instigators will similarly fail to appreciate how uncomfortable it is for actors to say "no" to their unethical requests. The potential impact 
of such a bias is clear. If we do not recognize the extent to which our unethical suggestions and actions are likely to affect others' behavior, we may be careless about the things we say and do.

Previous research has demonstrated that people tend not to recognize the influence they have over others when making prosocial requests. In a series of studies, Flynn and Lake (Bohns) (2008) had participants solicit a number of different help requests from passersby, e.g., asking people for the use of their cell phones, asking to be escorted to a location on campus, and soliciting donations for a charity. Before making these requests, participants were asked to estimate how many people they would have to approach in order to get someone to say "yes." Participants in these studies consistently overestimated — by as much as 50 percent — the number of people they would have to ask to get someone to agree to their requests for help, i.e., people were far more likely to say "yes" to these requests for help than participants expected (see also Flynn \& Bohns, 2012; Bohns et al., 2011; Newark, Flynn \& Bohns, in press).

Yet despite the robustness of this effect, it is unclear whether it is limited to the domain of prosocial behavior, or whether it is likely to generalize to other types of requests, for example, unethical requests. On one hand, participants in these studies may have simply underestimated others' helpfulness. On the other hand, participants may have underestimated the power of their own requests. This latter possibility is particularly important from a theoretical standpoint because it suggests that the Flynn and Lake (Bohns) effect may extend to a wider range of influence scenarios than originally thought. People may not simply be more likely to help us than we expect, but may be more likely to do what we ask than we expect, regardless of what we are asking. 
Further, it is not obvious that these findings would extend to unethical acts. Research on people's general impressions of others' prosocial nature and ethicality suggests that people tend not to think very highly of others' moral compasses. For example, research on the "holier than thou effect" (e.g., Balcetis, Dunning, \& Miller, 2008) has demonstrated that people see others as less moral than themselves. Similarly, research on the "norm of self-interest" (Miller, 1999) suggests that people see others as generally less charitable and more selfish than they actually are. Instigators may therefore view pressuring another person to engage in an unethical act to be a much easier feat than getting someone to engage in a prosocial act. For these reasons, it would be particularly noteworthy if the Flynn and Lake (Bohns) (2008) findings extended to the domain of unethical behavior.

We hypothesize that the same egocentric mechanism underlying the underestimation effect for prosocial requests will lead people to underestimate how likely others are to comply with their unethical requests. The tendency of help-seekers to underestimate the likelihood that their requests for help will be granted has been explained by a differential attention focus between help-seekers and potential helpers. Flynn and Lake (Bohns) found that potential helpers are particularly attuned to the social costs of saying "no," or the awkwardness and embarrassment of refusing someone's request. Yet help-seekers tend to ignore these face-saving concerns (Bohns \& Flynn, 2010; Sabini, Siepmann, \& Stein, 2001; Van Boven, Loewenstein, \& Dunning, 2005), attending instead to other information, such as the instrumental costs a potential helper would incur by agreeing to a request (DePaulo, 1983; Greenberg, 1980; Thibaut \& Kelley, 1959). These different foci in turn lead to divergent beliefs about compliance: 
potential helpers, focused on how awkward it would be to say "no," are quick to comply with a request for help, while help-seekers, oblivious to the awkward position helpers are in, think their requests for help are unlikely to be fulfilled.

We argue that instigators of unethical acts put actors in a similarly awkward position of feeling unable to say "no," and are also similarly oblivious to this fact. Much research has shown that social pressure is a remarkably powerful force in determining individuals' decisions regarding whether or not to commit unethical acts (Gino, Ayal, \&Ariely, 2009; Gino \& Galinsky, 2012; Gunia et al., 2012; Milgram, 1963; Monin, Sawyer \& Marquez, 2008; Webber, Schimel, Martens, Hayes, \& Faucher, 2013; see Moore \& Gino, 2013 for a recent review). Just as it is difficult to say "no" to someone who is asking for help, it is difficult to say "no" to someone who is pressuring one to engage in an unethical act. Further, instigators of unethical acts, like help-seekers, are likely focused on other factors, such as the potential consequences of the unethical act (Jones, 1991; Paharia et al, 2009). Instigators are therefore similarly likely to overlook the social costs to actors of saying "no." Once again, these different foci should lead to divergent beliefs about whether an actor is likely to participate in an unethical deed: focused on the awkwardness of standing up against social pressure, actors are likely to agree to go along with the unethical act, while instigators, oblivious to the awkward position they have put actors in, think it is unlikely they will comply.

\section{Overview of the Current Research}

In the current research, we tested the hypothesis that instigators would underestimate their influence over actors' unethical behavior and decisions, i.e., actors' decisions regarding whether or not to commit unethical acts, and how comfortable actors 
would feel choosing to "do the right thing." The current work extends the findings of Flynn and Lake (Bohns) in which help-seekers underestimated their ability to get potential helpers to comply with their requests for help. Accordingly, we conducted a series of four studies to test whether the original findings by Flynn and Lake (Bohns) would replicate in an unethical domain. In our first two studies, we had student participants enlist other students to commit actual unethical acts. In Study 1, participants enlisted their fellow students to tell a "white lie," and in Study 2 they convinced them to vandalize a library book. In both studies, participants made predictions about how effective they would be at getting others to commit these ethical transgressions, and we compared their predictions to how effective they actually were at getting others to engage in these acts.

In our last two studies, we assigned participants to the perspectives of "Actor," "Instigator," or "Neutral Observer" in hypothetical unethical scenarios in order to test the egocentric mechanism we have proposed for the underestimation of influence effect. We have suggested that instigators fail to fully appreciate the discomfort actors would experience by going against another person's suggestion to engage (or not engage) in an unethical act. As a result, instigators should be relatively insensitive to the effect their ethical suggestions have on actors. To test this prediction, we assessed instigators' beliefs about how uncomfortable actors would feel engaging in various unethical acts following their unethical or ethical advice and compared instigators' ratings to the discomfort actors themselves reported feeling after hearing such advice.

In all four studies, we predicted that instigators would underestimate the social pressure they imposed on others through their simple suggestions to engage (or not 
engage) in an unethical act. That is, instigators would not recognize how easily they could convince others to engage in unethical acts, and the extent to which their suggestions would affect others' feelings about potentially engaging in unethical acts.

\section{Study 1: Getting Others to Tell a "White Lie"}

In Study 1, university students enlisted other students to commit a "white lie." Before soliciting their fellow students, participants made a prediction about how easy it would be to get them to do so. We compared participants' beliefs about their capacity to get others to lie to their actual effectiveness at soliciting lies. This design provided us with an initial test of our predictions in a realistic context using tangible behavioral outcomes.

\section{Method}

\section{Participants}

Fifty-two "primary" participants (31 Female; 21 Male) were recruited through campus flyers and paid \$15 to solicit 198 “secondary” participants (104 Female; 94 Male). Seven primary participants dropped out of the study after reading the task instructions (before attempting to obtain any signatures) and were paid $\$ 5$ to complete only the pre-task questionnaire.

\section{Procedure}

Upon arrival to the lab, our "primary" participants were given a pre-task questionnaire. In this questionnaire, participants read the complete task instructions before answering any questions about the task. An excerpt is below:

"In this study, you will ask strangers (in person) to commit a small lie. The lie you will be asking them to commit is to sign a form stating that you have given them an 
introduction to a new course that is being offered by a Professor at UW. You will not in fact give an introduction to this course..."

Participants were also provided with the script they were to use when approaching people:

"Will you sign this? I'm supposed to tell students about a new course and get them to sign this form stating that they've heard about the course, but I really don't want to do it."

After learning the complete details of the task (no information was withheld), primary participants predicted how effective they would be at soliciting people to lie by providing a free-response answer to the question, "How many people do you think you will have to approach before you get 3 people to sign the signature sheet indicating that they've heard about the course you didn't tell them about?" This question was adapted for our purposes from Flynn and Lake (Bohns) (2008) ${ }^{1}$. To tap into their awareness of the social pressure they would impose on the individuals they solicited, primary participants' were also asked to indicate on a 7-point scale how comfortable the people they approached would feel saying "no" to their request.

Participants were then provided with the following materials for their task: 3 individual signature sheets stating, "My signature provided below indicates that the person who approached me gave me information about a new course at UW"; a pen; a tally sheet on which to record the responses and gender of each person they approached; debriefing forms for the secondary participants; a copy of the task instructions. Participants were sent to designated areas of campus to complete the task (to avoid multiple participants covering the same areas). Secondary participants who provided a 
bogus signature were subsequently told that they were part of a study and were assured that they had not in fact done anything wrong. They were then handed a debriefing sheet informing them about the details of the study. After getting 3 people to sign the forms, participants returned to the lab, completed a brief post-task questionnaire, and were thanked and paid. To ensure that all participants completed the task as instructed, participants were also thoroughly debriefed upon their return to the lab.

\section{Results}

We hypothesized that participants would underestimate their own influence over others' unethical behaviors by overestimating the number of individuals they would have to approach to get 3 individuals to commit this "white lie." One participant made a prediction of 300 people and was excluded from all analyses as an outlier (56 SDs from the Mean). The predictions made by the seven participants who dropped out of the study after reading about the task were significantly higher $(M=18.33, S D=19.19)$ than participants who completed the task (excluding the outlier: $M=8.47, S D=5.14), F(1$, $48)=8.28, p=.006$, suggesting that our results may be conservative.

\section{Predicted vs. Actual Compliance}

Our primary prediction that participants would overestimate the number of people they would have to approach to get 3 people to agree to lie was confirmed. We ran a repeated-measures ANOVA comparing participants' predictions of the number of people they would have to approach $(M=8.47, S D=5.14)$ to the actual number of people they had to approach before 3 people agreed to tell this "white lie" $(M=4.39, S D=2.37)$, and found a significant difference in predicted versus actual compliance, $F(1,43)=32.87, p<.001$ (see Figure 1). In fact, 40 of the 44 participants who completed the task (90.9\%) 
underestimated the proportion of people they could convince to lie, $\chi^{2}(1, N=44)=29.46$, $p<.001$. The fact that the proportion of participants who committed this error was so substantial suggests that this finding is not the result of a statistical anomaly.

\section{Social Pressure Mechanism}

To explore the relationship between participants' lack of awareness of the discomfort others" would feel saying "no" to their requests and their accuracy in predicting their influence over others' unethical behavior, we looked at the correlation between participants' predictions of the number of people they would have to approach to complete the task and their "comfortable saying "no" ratings $(M=4.13, S D=1.40$, Range=1-7). These two variables were highly positively correlated $r(44)=.48, p<.001$, indicating that the more participants took into account the discomfort others would feel refusing to lie (the lower their ratings), the fewer people they believed they would need to approach with their request. In other words, the more participants recognized the social pressure inherent in their request, the more effective they (correctly) imagined they would be at getting people to lie.

\section{Discussion}

As predicted, participants in Study 1 underestimated their ability to get others to engage in an unethical act, i.e., committing a white lie. However, it is possible that this "white lie" did not seem particularly unethical to the individuals being asked to commit it. The unethical act itself was relatively minor, thus it may have been a case of "no harm, no foul." Further, secondary participants may have focused more on the possibility that they were helping out a fellow student in need than on the fact that they were doing so by committing a lie. Although we believe that many coerced unethical acts may be 
committed under the guise of "helping someone out," we nonetheless felt it was important to replicate these findings with a more unmistakeably unethical act in Study 2.

\section{Study 2: Getting Others to Vandalize a Library Book}

Study 2 follows the same experimental design as Study 1. However, in this study, we used a more unequivocally unethical act: vandalizing a library book. University students once again solicited their fellow students to engage in this unethical action. Before doing so, they made predictions about how easy it would be to get other students to commit this act. We compared participants' beliefs about their capacity to get others to deface a library book to their actual effectiveness at getting others to do so.

\section{Method}

Twenty-five "primary" participants (23 Female; 2 Male) were recruited through the psychology department participant pool's recruitment website and paid $\$ 10$ to solicit 108 "secondary" participants (48 Female; 60 Male). Two primary participants dropped out of the study after reading the task instructions (before attempting the vandalism task) and were paid $\$ 5$ to complete only the pre-task questionnaire.

Upon arrival to the lab, our "primary" participants were again given a pre-task questionnaire. In this questionnaire, participants read the complete task instructions before answering any questions about the task. An excerpt is below:

"In this study, you will ask strangers (in person) to commit a small act of vandalism.

Specifically, you will ask them to write the word "pickle" on a page of a library book..."

Participants were also provided with the script they were to use when approaching people: 
"Hi, I'm trying to play a prank on someone, but they know my handwriting. Will you just quickly write the word 'pickle' on this page of this library book?"

After learning the complete details of the task (again, no information was withheld), participants predicted how effective they would be at soliciting people to vandalize the book by providing a free-response answer to the question, "How many people do you think you will have to approach before you get 3 people to agree to write the word 'pickle' in a library book?" To tap into their awareness of the social pressure they imposed on those they solicited, participants were asked the same question asked of participants in Study 1. They were asked to indicate on a 7-point scale how comfortable the people they approached would feel refusing their request.

Participants were then provided with the following materials for their task: a hardcover book with a library reference number taped to the spine (the book was made to look identical to library books at the university campus library; see Figure 2); a pen; a tally sheet on which to record the responses and gender of each person they approached; debriefing forms for the secondary participants; a copy of the task instructions. Once again, participants were sent to designated areas of campus to complete the task (to avoid multiple participants covering the same areas).

Secondary participants' verbal responses to the request, as recorded by the primary participants in a "comments" section of their tally sheets, gave us confidence that this act was indeed perceived as unethical by those who were asked to engage in it. A number of participants stated that they would not write in a library book, others asked to use pencil instead of $p^{2}{ }^{2}$, some expressed concern about the possibility that 
they or the primary participant would get into trouble, and others explicitly referred to the act as vandalism (see Table 1 for selected quotes from secondary participants).

Individuals who agreed to write in the fake library book were subsequently told that they were part of a study, and were assured that the book was not a library book and that they had not in fact done anything wrong. They were then handed a debriefing sheet informing them about the details of the study. After getting 3 people to write on separate, clean pages of the book (in pen; see Figure 2 for an example), primary participants returned to the lab and were thanked and paid. Once again, to ensure that all participants completed the task as instructed, primary participants were thoroughly debriefed upon their return to the lab.

\section{Results}

We hypothesized that participants would underestimate their own influence over others' unethical behaviors by overestimating the number of individuals they would have to approach to get 3 individuals to commit this small act of vandalism ${ }^{3}$.

\section{Predicted vs. Actual Compliance}

Our primary prediction that participants would overestimate the number of people they would have to approach was confirmed. We ran a repeated-measures ANOVA comparing participants' predictions of the number of people they would have to approach $(M=10.73, S D=6.58)$ to the actual number of people they had to approach before 3 people agreed to vandalize the library book $(M=4.70, S D=2.53)$, and again found a significant difference in predicted versus actual compliance, $F(1,22)=16.72, p<.001$ (Figure 1). In this study, twenty of the 23 participants who completed the task $(87.0 \%)$ underestimated the proportion of people they could convince to vandalize the book, $\chi^{2}(1, N=23)=12.57$, 
$p<.001$.

\section{Social Pressure Mechanism}

We again examined the relationship between participants' "comfortable saying 'no"' ratings $(M=4.72, S D=1.49$, Range $=1-7)$ and their predictions of the number of people they would have to approach in order to complete the task. These two variables were again positively correlated $r(24)=.31, p=.11$ (although not significantly), indicating once again that the more participants took into account the discomfort others would feel refusing their suggestions, the fewer people they believed they would need to approach to complete the task.

\section{Discussion}

The findings of Study 2 are highly consistent with those of Study 1 (see Figure 1). Once again, participants underestimated how easy it would be to get their fellow students to engage in an unethical act - in this case, the act of defacing a library book, a more unequivocally unethical deed. Further, their predictions of how difficult the task would be (i.e., how many people they would have to approach to get 3 individuals to write in the book) were once again correlated with their estimates of how comfortable the people they approached would feel saying "no" to them. (However, in this case the correlation was marginally significant, likely due to the smaller sample size in this study.)

Although these findings appear to provide strong support for the prediction that individuals underestimate the extent to which they can influence others' willingness to engage in unethical acts, these studies still leave open some alternative explanations. For example, since to some extent these studies required the primary participants to act (e.g., by pretending they were supposed to be giving a marketing pitch for a new course), 
primary participants may have underestimated their acting abilities rather than their persuasive abilities. Or, as research on the "illusion of transparency" (Gilovich, Savitsky, $\&$ Medvec, 1998) might suggest, participants may have imagined that their own discomfort with the task would "leak out," becoming apparent to those they approached and thus undermining their ability to convince people to engage in these unethical acts. Also, although we are convinced through our debriefings with participants and the comments they recorded on their tally sheets that they did indeed complete the task as described, we cannot be absolutely sure that some participants did not simply immediately inform the individuals they approached of the purpose of the study. Another possibility is that participants may have envisioned the task very differently beforehand, and found it much easier to select those individuals who were likely to be compliant (e.g., those sitting around doing nothing) when they actually went out to perform the task.

In addition, Studies 1 and 2 do not provide specific evidence for the egocentric mechanism we have proposed whereby instigators fail to account for the social pressure they impose on actors. In these studies, we can only compare primary participants' "comfortable saying 'no"” ratings to their own predictions of compliance, rather than to secondary participants' own ratings of discomfort. As a result, we do not know whether primary participants were indeed underestimating the social pressure they were imposing on secondary participants, i.e., the discomfort secondary participants would have experienced by refusing their requests.

In Studies 3 and 4, we attempted to rectify these issues by experimentally assigning participants to the perspectives of "Actor" and "Instigator" (and "Neutral Observer," in Study 4) in a series of hypothetical unethical scenarios. The hypothetical 
nature of these studies gave us more experimental control and therefore helped to eliminate some of the issues we faced by sending participants out in the field. Further, the random assignment to perspective allowed us to compare instigators' beliefs about how uncomfortable their unethical suggestions would make actors to actors' own ratings of discomfort.

\section{Study 3: Manipulating Perspective in Hypothetical Scenarios}

In Study 3, we randomly assigned participants to the perspectives of "Actor" or "Instigator" in hypothetical unethical scenarios to test the prediction that our findings in Studies 1 and 2 were the result of Instigators' egocentric failure to recognize the discomfort experienced by Actors. We wanted to (a) confirm that Actors do indeed find it less comfortable to "do the right thing" when faced with an Instigator's unethical suggestion, and (b) test our primary prediction that Instigators are insensitive to the impact of their suggestions on the discomfort actors feel doing the right thing, i.e., the social pressure inherent in their suggestions.

\section{Method}

One hundred seventy-one participants (90 Female; 81 Male) were recruited through Amazon Mechanical Turk and paid $\$ 1.00$ to complete an online survey.

The study was a 2(Perspective: Actor, Instigator) $\times 2$ (Suggestion: No Suggestion, Unethical Suggestion) between-subjects design. Participants read 4 scenarios describing ambiguously unethical situations: buying beer for underage kids, giving someone prescription Valium, downloading a movie illegally, and reading a colleague's private Facebook messages. See Appendix A for complete scenarios.

\section{Perspective Conditions}


In the Actor condition, participants read all four scenarios from the perspective of the person deciding whether or not to engage in each unethical behavior. For example, in the "Facebook" scenario, Actors are seated at a colleague's computer, and she has not logged out of her Facebook account, which contains private messages. In the Instigator condition, participants read the scenarios from the perspective of a friend or co-worker who was part of the situation, but not the final decision-maker. For example, in the "Facebook" scenario, Instigators look over the Actor's shoulder, but do not have access to the computer themselves.

\section{Suggestion Conditions}

In the unethical suggestion condition, the Instigator suggests that the Actor go ahead and engage in the unethical behavior. For example, in the "Facebook" scenario, participants would read, "you lean over [your work partner leans over]... and say[s], 'Nice. Check out her messages..."' In the no suggestion condition, this sentence is omitted.

\section{Social Pressure Dependent Variable}

After reading each scenario, all participants answered the same social pressure question our primary participants answered in Studies 1 and 2. Specifically, participants assessed how comfortable actors would feel doing the ethical thing in each scenario on a scale of 1 (Not at all) to 7 (Extremely), i.e., "How comfortable would someone feel refusing [trying not] to read their colleague's messages in this situation?" In the unethical suggestion condition, this meant that actors would be going against the Instigator's suggestion to engage in an unethical act, which is essentially comparable to a secondary participant saying "no" to a primary participant in Studies 1 and 2. 


\section{Results}

We tested our hypothesis with a 2(Perspective: Actor, Instigator) $\times 2$ (Suggestion: Unethical Suggestion, No Suggestion) $\times$ 4(Individual Scenarios) mixed-model ANOVA. The content of the scenarios did not affect the pattern of results, $F(1,167)<1.6$, so our findings are reported collapsed across scenarios.

\section{Main Effects}

There was an overall main effect of Perspective, $F(1,167)=9.61, p=.002$, indicating that participants in the Actor condition $(M=5.23, S D=1.16)$ reported feeling more comfortable doing the ethically right thing overall than participants in the Instigator condition $(M=4.68, S D=1.08)$ thought Actors would feel. This finding is consistent with the "myth of self-interest" (Miller, 1999) from the Instigator's perspective and a selfserving bias (Heider, 1958) from the Actor's perspective. There was also an overall main effect of Suggestion, indicating, not surprisingly, that participants thought the Actor would feel more comfortable doing the ethically right thing when the Instigator said nothing $(M=5.31, S D=1.10)$ than when the Instigator suggested doing the unethical thing $(M=4.67, S D=1.16), F(1,169)=13.92, p<.001$.

\section{Perspective $\times$ Suggestion Interaction}

As predicted, there was a significant interaction of Perspective $\times$ Suggestion on how comfortable participants thought someone would feel doing the ethically right thing, $F(1,167)=3.98, p=.05$ (see Figure 3). Participants in the Actor perspective felt significantly less comfortable doing the ethically right thing when the Instigator made an unethical suggestion $(M=4.75, S D=1.15)$ than when no suggestion was made $(M=5.65$, $S D=1.01), F(1,99)=17.66, p<.001$. However, participants in the Instigator perspective 
failed to recognize the effect their unethical suggestion would have on the Actor.

Instigator's ratings of comfort did not vary between the unethical suggestion $(M=4.56$, $S D=1.11)$ and no suggestion $(M=4.79, S D=1.05)$ conditions, $F(1,68)<1$.

\section{Discussion}

These findings support an egocentric explanation for our findings in Studies 1 and 2. Participants who were randomly assigned to the perspective of Actor felt less comfortable "doing the right thing" across a variety of hypothetical unethical scenarios when another person - an Instigator - suggested they do the unethical thing. However, participants who were randomly assigned to the perspective of Instigator did not pick up on this difference, i.e., they did not recognize the effect that their unethical suggestion had on Actors compared to a condition in which they said nothing.

While these findings are consistent with our theory, there are a few noteworthy shortcomings of this study. First, we did not include a Neutral Observer condition, which would help us to identify the direction of the effect. Accordingly, in Study 4, we added a Neutral Observer condition.

Second, in this study, we compared an unethical suggestion condition to a no suggestion condition. In the condition in which no suggestion was offered, participants' estimates of how comfortable someone would feel "doing the right thing" would have been based purely on their preconceptions about how comfortable someone would feel doing the right thing in general, rather than their theories about how social influence affects their own or others' decisions. Thus, in Study 4, we contrasted an unethical advice condition to an ethical advice condition so that both conditions involved social pressure, but in opposing directions. 
Third, some of the scenarios in Study 3 implicated both the Instigator and the Actor; that is, the Instigator was not merely advising the Actor, but acting jointly with him or her. However, even individuals who are simply advising an Actor on an ethical dilemma without facing any ramifications of the decision for themselves should underestimate the power of their opinion to influence the Actor. Further, in the Study 3 scenarios, Actors may have felt in some way that they were helping the Instigator (e.g., by going along with what the Instigator wanted to do), which would have made our scenarios too similar to the scenarios used by Flynn and Lake (2008; Studies $4 \& 5$ ). Thus, we created new ethical dilemma scenarios for Study 4 that would affect and implicate only the Actor, eliminating the possibility that Actors would reinterpret their behavior as a prosocial act.

\section{Study 4: Manipulating Perspective in Hypothetical Scenarios with a Neutral}

\section{Observer Condition}

In Study 4, we attempted to replicate our findings from Study 3 as well as extend them in three primary ways. First, we added a Neutral Observer perspective condition.

Second, we included two social influence conditions - an unethical advice condition, and an ethical advice condition - rather than comparing a condition in which an Actor received unethical advice to a more ambiguous condition in which he or she received no advice. Third, we created a new set of scenarios in which the Instigators were not complicit in the unethical acts, and therefore bore no responsibility nor reaped rewards for the acts. In these scenarios, Instigators simply gave Actors advice about an ethical dilemma Actors were facing alone. Once again, participants were assigned to different 
perspectives and asked to read a series of vignettes. In this case, they were assigned to one of three perspectives: "Actor," "Instigator," or "Neutral Observer."

\section{Method}

One hundred fifty-five participants were recruited through Amazon Mechanical Turk and paid $\$ 1.00$ to complete an online survey.

The study was a 3(Perspective: Actor, Instigator, Neutral Observer) $\times 2$ (Advice: Ethical Advice, Unethical Advice) between-subjects design. Participants once again read 4 scenarios describing ambiguously unethical situations; however, in this case, the unethical decisions affected only the Actor, not the Instigator. The scenarios involved calling in sick to work to go to a baseball game, taking home office supplies (reams of paper) for personal use, freelancing for a corporate competitor, and putting personal dinners on a professional expense report. The scenarios were inspired by Wiltermuth and Flynn (2013)'s morally ambiguous work dilemmas, and the complete scenarios can be found in Appendix B.

\section{Perspective Conditions}

As in Study 3, participants in the Actor condition read all four scenarios from the perspective of the person deciding whether or not to engage in each unethical behavior. For example, in the "Calling in Sick to Work" scenario, Actors are offered last-minute tickets to a baseball game and must decide whether to call in sick the next day in order to attend. In the Instigator condition, participants once again read the scenarios from the perspective of a friend or co-worker who is listening to the Actor's dilemma, but is uninvolved in the situation and unaffected by the Actor's decision. For example, in the "Calling in Sick to Work" scenario, Instigators are simply having drinks with the Actor 
after work, and the Actor tells the Instigator about his or her dilemma regarding whether to call in sick. In the Neutral Observer condition, participants simply imagine each of the scenarios happening to two unknown individuals. Neutral Observers have no role in the situation themselves. For example, they are asked to imagine that someone is faced with the dilemma of deciding whether to call in sick from work, and that this person has shared this dilemma with a co-worker over drinks.

\section{Advice Conditions}

We had an unethical advice condition and an ethical advice condition. In the unethical advice condition, the Instigator suggests that the Actor go ahead and engage in the unethical behavior. For example, in the "Calling in Sick to Work" scenario, the Instigator says, "Sure, if it was me, I would totally do that." In the ethical advice condition, the Instigator suggests that the Actor not engage in the unethical behavior. For example, in this scenario, the Instigator says, “I don’t know. If it was me, I probably wouldn't do that."

\section{Social Pressure Dependent Variable}

After reading each scenario, participants answered the same social pressure question participants responded to in Studies 1, 2, and 3. However, in this case, the question involved how comfortable Actors would feel doing the unethical thing, rather than the ethical thing. That is, after reading each scenario, participants answered a question on a 7-point scale about how comfortable they thought actors would feel doing the unethical thing e.g., "How comfortable would someone feel calling in sick to take the day off from work?"4

\section{Results}


We tested our hypothesis with a 3(Perspective: Actor, Instigator, Neutral Observer $) \times 2($ Advice: Unethical, Ethical $) \times 4($ Individual Scenarios $)$ mixed-model ANOVA. The content of the scenarios once again did not affect the pattern of results, $F(1,149)<1$, so our findings are reported collapsed across scenarios.

\section{Main Effects}

There was an overall main effect of Perspective, $F(1,149)=24.69, p<.001$, indicating that participants in the Actor condition $(M=2.84, S D=1.24)$ reported feeling less comfortable engaging in unethical acts overall than participants in the Neutral Observer condition $[M=3.65, S D=.89, F(1,108)=15.93, p<.001]$ and the Instigator condition $[M=4.20, S D=.78, F(1,88)=38.40, p<.001]$ thought Actors would feel. This finding is again consistent with the "myth of self-interest" (Miller, 1999) from the Neutral Observer's and Instigator's perspectives and a self-serving bias (Heider, 1958) from the Actor's perspective. Interestingly, Instigators thought Actors would feel significantly more comfortable engaging in unethical acts than did Neutral Observers, $F(1,112)=11.27, p=.001$, suggesting that there is something unique about the "instigator" perspective that makes it different from the "neutral observer" perspective. There were no main effects of Advice condition.

\section{Perspective $\times$ Advice Interaction}

As predicted, there was a significant interaction of Perspective $\times$ Advice on how comfortable participants thought someone would feel engaging in unethical acts, $F(1$, 149) $=3.63, p=.03$ (see Figure 4). Participants in the Actor perspective reporting feeling more comfortable doing unethical things when the instigator gave them unethical advice $(M=3.13, S D=1.17)$ than when the instigator gave ethical advice $(M=2.38, S D=1.25)$, 
$F(1,41)=3.87, p=.056$. However, participants in the Instigator perspective once again failed to recognize the effect their advice would have on the actor. Their ratings of comfort did not vary between the unethical advice $(M=4.08, S D=.65)$ and ethical advice $(M=4.32, S D=.89)$ conditions, $F(1,44)=1.08, p=.30$. Neutral Observers' ratings also did not vary between the unethical advice $(M=3.55)$ and ethical advice $(M=3.72)$ conditions, $F(1,66)=.59, p=.44$.

\section{Discussion}

We replicated our findings from Study 4 using ethical dilemmas that affected the Actor only. Once again, Actors were influenced by the advice they received from Instigators, but Instigators failed to recognize the power of their advice to influence Actors. Consistent with previous research (e.g., Bohns \& Flynn, 2010; Sabini, Siepmann \& Stein, 2001; Van Boven, Lowenstein \& Dunning, 2005) Neutral Observers also failed to recognize the extent to which Actors were affected by social pressure. These findings provide further evidence for an egocentric explanation of our findings in Studies 1 and 2.

Notably, our main effects analyses revealed differences in the judgments of neutral observers and instigators, suggesting that these are different perspectives that should be studied independently. However, because neither group appreciated the role of social influence, the two perspectives appear to be limited by similar cognitive biases or constraints.

\section{General Discussion}

In four studies, we found that instigators failed to recognize their influence over actors, i.e., the social pressure they levied on actors through simple unethical suggestions. In Studies 1 and 2, participants underestimated how easy it would be to get their fellow 
students to engage in unethical acts (i.e., telling a "white lie," and vandalizing a library book). Not only were participants' predictions skewed towards underestimation in these studies, more than $90 \%$ of our sample in Study 1 and $87 \%$ in Study 2 erred in this direction. In Studies 3 and 4, participants randomly assigned to the role of "actor" felt significantly less comfortable doing the "right thing" (more comfortable doing the "wrong thing" in Study 4) in a series of hypothetical ethical dilemmas if an instigator had given them unethical advice. However, participants assigned to the role of "instigator" did not recognize the influence their unethical suggestions had on actors' feelings about these unethical acts.

\section{Theoretical Contributions}

Although social psychology has mined the differing perspectives of "actors" and "observers," there is very little, if any, research on the psychology of "instigators" of others' behavior, particularly their unethical behavior. Such research is important because in many situations we are not simply passive observers of others' behavior, but are actually inciters or instigators of their behavior. That is, we are active participants in a situation, attempting to explain and predict others' behavior while we are simultaneously influencing it (Neisser, 1980). The current work takes a step towards closing this knowledge gap by examining active participants in social situations.

The current work also suggests a broader interpretation of the original Flynn and Lake (Bohns) (2008) effect by extending the original findings to the realm of unethical behavior. It appears that we not only underestimate the likelihood that others will help us. Rather, we underestimate the extent to which we can influence others to engage in a variety of behaviors with a simple request. Taken together, the current findings and the 
original Flynn and Lake (Bohns) findings suggest that we may underestimate the influence we have over others more generally.

The possibility that we underestimate our influence over others is surprising in light of research on the "illusion of control" (Langer, 1975), overconfidence (Alicke \& Govorun, 2005; Dunning, Heath, \& Suls, 2004; Moore \& Healy, 2008), and magical thinking (Pronin et al., 2006), all of which have demonstrated a tendency to overestimate one's influence in a variety of situations. These seemingly conflicting findings may represent different types of attribution processes. Hamilton (1980) makes a distinction between causal attributions, which seek to answer the question, "Did the behavior I engaged in lead to the behavior someone else subsequently engaged in?" and attributions of responsibility, which seek to answer the question, "Could the individual have done otherwise?" That is, a preceding behavior by one person may indeed "pull for" a subsequent behavior by another person, but if the latter person can choose to do something else, he or she is ultimately responsible for his or her behavior (see Bohns \& Flynn, 2013 for a more detailed discussion).

The obvious difference between the outcomes typically used in illusion of control and overconfidence paradigms (e.g., lottery tickets, IQ tests) and actors' behaviors in our studies is that people have intentionality. When we try to determine whether or not we influenced a physical outcome (a dice roll, the changing of a light), we need only answer Hamilton's first question about causality. On the other hand, when determining whether or not we influenced another person's behavior, considering contingency and our own intentions alone cannot provide a satisfactory answer. To understand another person's behavior, we also need to consider the other person's intentions and answer Hamilton's 
second question regarding responsibility. Such a determination requires perspectivetaking, a process at which people are notoriously flawed (Epley, Keysar, Van Boven, \& Gilovich, 2004)

\section{Limitations and Future Directions}

The current studies provide compelling evidence that people underestimate the extent to which their suggestions affect others' ethical behaviors and decisions. However, exactly what specific social pressure information instigators are overlooking and actors are attending to is less clear. Actors may be willing to "bend the rules" for other people for many different reasons. An instigator's unethical suggestion may establish a descriptive norm (Cialdini, 2007), actors may reinterpret an unethical act as a prosocial act in which they are helping the instigator out, or actors may simply hope to stay in the good graces of the in-group. Any of these potential motivations may be lost on instigators. Future research may help to disentangle these various alternatives.

The possibility that actors reinterpret or reframe an unethical act as a prosocial act, in particular, may have played a role in a few of the scenarios in the current work. In general, people are motivated to see their behaviors in a positive light, and as a result they will often reinterpret an unethical behavior in prosocial terms (Gino, Ayal, \& Ariely, 2013; Gino \& Pierce, 2010; Shalvi et al., 2011; Wiltermuth, 2011). Although this may have been a concern in Studies 1 and 3 in the current research, we believe that Studies 2 and 4 address this issue. While the unethical act was relatively ambiguous and negligible in Study 1, many of the individuals who were approached with the vandalism task in Study 2 commented explicitly about the fact that the task was unethical. Further, while some of the scenarios in Study 3 involved joint-action and could therefore triggered a 
motivation for instigators to reframe the behavior so as not to implicate themselves, in Study 4 instigators were merely advising actors who would be engaging in the behavior independently and with no costs or benefits for the instigator. Yet, as mentioned earlier, many unethical behaviors are in fact conducted under the guise of helping someone out, so it may be worthwhile in future research to tease apart instigators' potential neglect of the prosocial reframing actors may engage in to cope with the unethical behaviors they may enact under pressure.

On the other hand, instigators may also have been motivated to see their behavior in a more positive light, which may have influenced their judgments. Instigators may not want to believe that someone else's unethical behavior is attributable to something they said or did and may therefore rationalize that their influence over the actor was likely to be minimal. However, if this possibility were true, we would have expected to find a difference between the perspectives of instigators, who have a stake in the unethical act, and neutral observers, who do not, in Study 4. Yet both neutral observers and instigators failed to appreciate the power of social pressure to influence actors' behaviors.

Another potential area for future research is an exploration of the cultural antecedents of the tendency to discount social pressure and norms as explanations for people's behavior. This tendency may be especially prevalent in relatively individualistic cultures. Members of individualistic cultures are believed to act largely of their own volition - doing something only if it is consistent with their own personal wishes - rather than out of a sense of obligation or social pressure (Markus \& Kitayama, 1991; Triandis, 1995). Conversely, in collectivistic cultures, the needs and goals of the group are supposed to usurp individual desires and personal interests (Markus \& Kitayama, 1991). 
Consequently, members of collectivistic cultures may be more aware of how social pressures shape their own and others' behavior.

Cross-cultural research supports this prediction. When Flynn and Lake's (Bohns) (2008) studies were replicated in a relatively individualistic culture, i.e., the United States, and a relatively collectivistic culture, i.e., China, the predictions of compliance made by Chinese help-seekers were more calibrated than those made by the American participants (Bohns et al., 2011). Although the underestimation effect was still present in both groups, it was attenuated in the more collectivistic culture. Further, Mazar and Aggarwal (2011) found that individuals who rated higher in collectivism were more likely to attribute unethical acts to the social context, rather than to their own personal will. Together, this research suggests that the current findings may also be attenuated in a more collectivistic culture.

\section{Conclusion}

Although it is common, particularly in individualistic cultures, to assume that the ethical decisions people make are the product of some unwavering personal integrity (or lack thereof), our research and others' (e.g., Gino, Ayal \& Ariely, 2009; Gino \& Galinsky, 2012; Moore \& Gino, 2013) reveals the large role the social context plays in such decisions. Yet, the surprising aspect of our research is not the finding that people will agree to tell a small lie when asked, or feel more comfortable engaging in an unethical behavior when a friend condones it. The truly startling finding is the lack of awareness people appear to have of this tendency when they are in a position to influence someone else's ethical behavior. Overall, the current research suggests that we may not recognize the extent to which our words and actions affect others' ethical behavior and 
decisions. In an era where auditing agencies communicate openly with the companies they audit (Morgenson, 2008), the social dynamics of trading rooms can foster shockingly unethical risky shifts (McLean \& Elkind, 2003), and cyber-bullying can have unimaginably dire consequences (Maag, 2007), the question of whether we as individuals understand the extent to which we contribute to a social norm, a collective value system, or simply another individual's assessment of the appropriate course of action in a given situation has important real-world implications. 


\section{Footnotes}

${ }^{1}$ Flynn and Lake (Bohns) had participants obtain help from 1, 3, or 5 people, depending on the study, and this number did not affect their pattern of results across studies. To keep our study within a reasonable time limit while obtaining enough data to accurately assess actual compliance, we decided to use the intermediate value from Flynn and Lake (Bohns)'s paper and require participants to get 3 signatures.

${ }^{2}$ Secondary participants who asked to write in pencil were told they had to write with the participant's pen.

${ }^{3}$ The number of participants who dropped out of this study (2 participants) was too small to compare their predictions to the predictions of participants who completed the study.

${ }^{4}$ This question made more logical sense in the context of the revised scenarios than a question about, for example, how comfortable someone would feel not calling in sick to take the day off from work. 


\section{References}

Alicke, M. D., \& Govorun, O. (2005). The better-than-average effect. The self in social judgment (pp. 85-106). New York, NY, US: Psychology Press, New York, NY.

Balcetis, E., Dunning, D., \& Miller, R. L. (2008). Do collectivists know themselves better than individualists? cross-cultural studies of the holier than thou phenomenon. Journal of Personality and Social Psychology, 95(6), 1252-1267.

Bohns, V. K., \& Flynn, F. J. (2010). "Why didn’t you just ask?" underestimating the discomfort of help-seeking. Journal of Experimental Social Psychology, 46(2), 402409.

Bohns, V. K. \& Flynn, F. J. (2013). Underestimating our influence over others at work. Forthcoming in Research in Organizational Behavior.

Bohns, V. K., Handgraaf, M. J. J., Sun, J., Aaldering, H., Mao, C., \& Logg, J. (2011). Are social prediction errors universal? predicting compliance with a direct request across cultures. Journal of Experimental Social Psychology, 47(3), 676-680.

Cialdini, R. B. (2007). Descriptive social norms as underappreciated sources of social control. Psychometrika, 72(2), 263-268.

DePaulo, B. M. (1983). Perspectives on help seeking. New Directions in Helping, 2, 312. 
Dunning, D., Heath, C., \& Suls, J. M. (2004). Flawed self-assessment: Implications for health, education, and the workplace. Psychological Science in the Public Interest, 5(3), 69-106.

Epley, N., Keysar, B., Van Boven, L., \& Gilovich, T. (2004). Perspective taking as egocentric anchoring and adjustment. Journal of Personality and Social Psychology, 87(3), 327-339.

Flynn, F. J., \& Bohns, V. K. (2012). Underestimating One's Influence in Help-Seeking. Six Degrees of Social Influence: Science, Application, and the Psychology of Robert Cialdini (pp. 14-26). New York: Oxford University Press.

Flynn, F. J., \& Lake, V. K. B. (2008). If you need help, just ask: Underestimating compliance with direct requests for help. Journal of Personality and Social Psychology, 95(1), 128-143.

Gilovich, T., Savitsky, K., \& Medvec, V. H. (1998). The illusion of transparency: Biased assessments of others' ability to read our emotional states. Journal of Personality and Social Psychology, 75, 332-346.

Gino, F., Ayal, S., \& Ariely, D. (2013). Self-serving altruism? The lure of unethical action that benefits others. Journal of Economic Behavior \& Organization.

Gino, F., Ayal, S., \& Ariely, D. (2009). Contagion and differentiation in unethical behavior: The effect of one bad apple on the barrel. Psychological Science, 20(3), 393-398. 
Gino, F., \& Galinsky, A. D. (2012). Vicarious dishonesty: When psychological closeness creates distance from one's moral compass. Organizational Behavior and Human Decision Processes, 119(1), 15-26.

Gino, F. \& Pierce, L. (2010). Lying to level the playing field: Why people may dishonestly help or hurt others to create equity. Journal of Business Ethics, 95, 89103.

Gunia, B. C., Wang, L., Huang, L., Wang, J., \& Murnighan, J. K. (2012). Contemplation and conversation: Subtle influences on moral decision making. Academy of Management Journal, 55, 13-33.

Greenberg, M. S. (1980). A theory of indebtedness. In K. J. Gergen, M. S. Greenberg, \& R. H. Willis (Eds.), Social exchange: Advances in theory and research. New York: Plenum.

Hamilton, V. L. (1980). Intuitive psychologist or intuitive lawyer? Alternative models of the attribution process. Journal of Personality and Social Psychology, 39, 767772.

Heider, F. (1958). The psychology of interpersonal relations. New York: Wiley. Jones, T. M. (1991). Ethical decision making by individuals in organizations: An issue-contingent model. The Academy of Management Review, 16, 366-395

Langer, E. J. (1975). The illusion of control. Journal of Personality and Social Psychology, 32(2), 311-328. 
Van Boven, L. Loewenstein, G., \& Dunning, D. (2005). The illusion of courage in social predictions: Underestimating the impact of fear of embarrassment on other people. Organizational Behavior and Human Decision Processes, 96, 130-141.

Maag, C. (November 28, 2007). "A hoax turned fatal draws anger but no charges." New York Times.

Markus, H. R., \& Kitayama, S. (1991). Culture and the self: Implications for cognition, emotion, and motivation. Psychological Review, 98(2), 224-253.

Mazar, N., \& Aggarwal, P. (2011). Greasing the palm: Can collectivism promote bribery? Psychological Science, 22(7), 843-848.

McLean, B. \& Elkind, P. (2003). The smartest guys in the room: The amazing rise and scandalous fall of Enron. New York: Portfolio.

Milgram, S. (1963). Behavioral study of obedience. Journal of Abnormal Psychology, 67, $371-378$.

Miller, D. T. (1999). The norm of self-interest. American Psychologist, 54(12), 10531060.

Moore, D. A., \& Healy, P. J. (2008). The trouble with overconfidence. Psychological Review, 115(2), 502-517. 
Monin, B., Sawyer, P. J., \& Marquez, M. J. (2008). The rejection of moral rebels:

Resenting those who do the right thing. Journal of Personality and Social Psychology, 95(1), 76-93.

Moore, C. \& Gino, F. (2013). Ethically adrift: How others pull our moral compass from True North, and how we can fix it. Forthcoming in Research in Organizational Behavior.

Morgensen, G. (December 7, 2008). “Debt watchdogs: Tamed or Caught Napping?” New York Times.

Neisser, U. (1980). On "social knowing.". Personality and Social Psychology Bulletin, 6(4), 601-605.

Newark, D., Flynn, F. \& Bohns, V. K. (in press). One bitten, twice shy: The effect of a past refusal on expectations of future compliance. Social Psychological and Personality Science.

Paharia, N., Kassam, K. S., Greene, J. D. \& Bazerman, M. H. (2009). Dirty work, clean hands: The moral psychology of indirect agency. Organizational Behavior and Human Decision Processes, 2, 134-141.

Pronin, E., Wegner, D. M., McCarthy, K. \& Rodriguez, S. (2006). Everyday magical powers: The role of apparent mental causation in the overestimation of personal influence. Journal of Personality and Social Psychology, 91, 218-231. 
Reno, R. R., Cialdini, R. B., \& Kallgren, C. A. (1993). The transsituational influence of social norms. Journal of Personality and Social Psychology, 64(1), 104-112.

Sabini, J., Siepmann, M., \& Stein, J. (2001). The really fundamental attribution error in social psychological research. Psychological Inquiry, 12(1), 1-15.

Shalvi, S., Dana, J., Handgraaf, M. J. J., \& De Dreu, C. K. W. (2011). Justified ethicality: Observing desired counterfactuals modifies ethical perceptions and behavior. Organizational Behavior and Human Decision Processes, 115, 181-190.

Thibaut, J. W., \& Kelley, H. H. (1959). The social psychology of groups. New York: Wiley.

Triandis, H. C. (1995). Is recent psychology not pertinent for the study of values? Psyccritiques, 40(4), 339-340.

Webber, D., Schimel, J., Martens, A., Hayes, J., \& Faucher, E. H. (2013). Using a bugkilling paradigm to understand how social validation and invalidation affect the distress of killing. Personality \& Social Psychology Bulletin, 39(4), 470-481.

Wiltermuth, S. S. (2011). Cheating more when the spoils are split. Organizational Behavior and Human Decision Processes, 115, 157-168

Wiltermuth, S. S. \& Flynn, F. J. (2013). Power, moral clarity, and severity of punishment in the workplace. Academy of Management Journal. In Press. 
Table 1. A sample of secondary participants' responses to the request to vandalize a

library book in Study 2, as recorded by primary participants.

Sure, this is a library book?

On a library book? Whoa. Yeah, okay, sure.

I don't write on library books. Sorry about that.

So this is like vandalism? Okay, there, you got my autograph.

I wouldn't write on a library book

Nahhh, it's a library book

Why would I do that? It is a library book.

Is this from the library? I don't think we should write in the book.

I gotta vandalize this pretty book?

Shouldn't you use a pencil?

I'm not sure if I should...it's a library book?

Are you sure? Um, okay.

Pickle? Are you sure? It's a good book.

Let's do it.

Yeah, why in pen though?

Are you sure I can write in this?

Don't want to write in a library book

Not in pen in a library book

Only if I won't get in trouble

I dunno, it's a nice book

Can I write in pencil?

Great, what prank are you playing? I hope you don't get into sh $\& * \%$ for this!

Is that a library book? 
Figure 1. Participants overestimated the number of people they would have to approach to get 3 individuals to agree to commit an unethical act (i.e., telling a white lie, or committing an act of vandalism) in Studies 1 and 2.

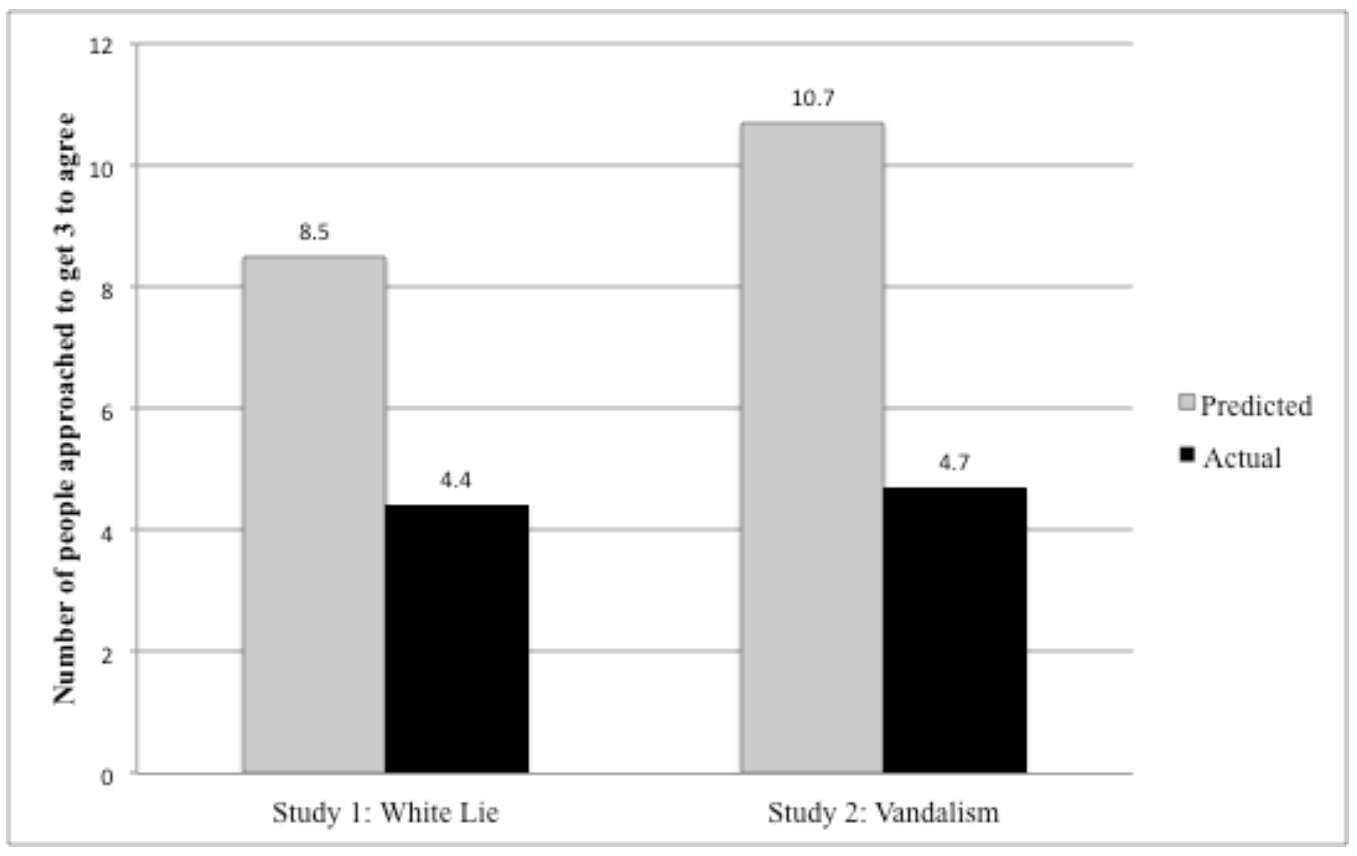


Figure 2. Fake library book vandalized by a secondary participant in Study 2 .

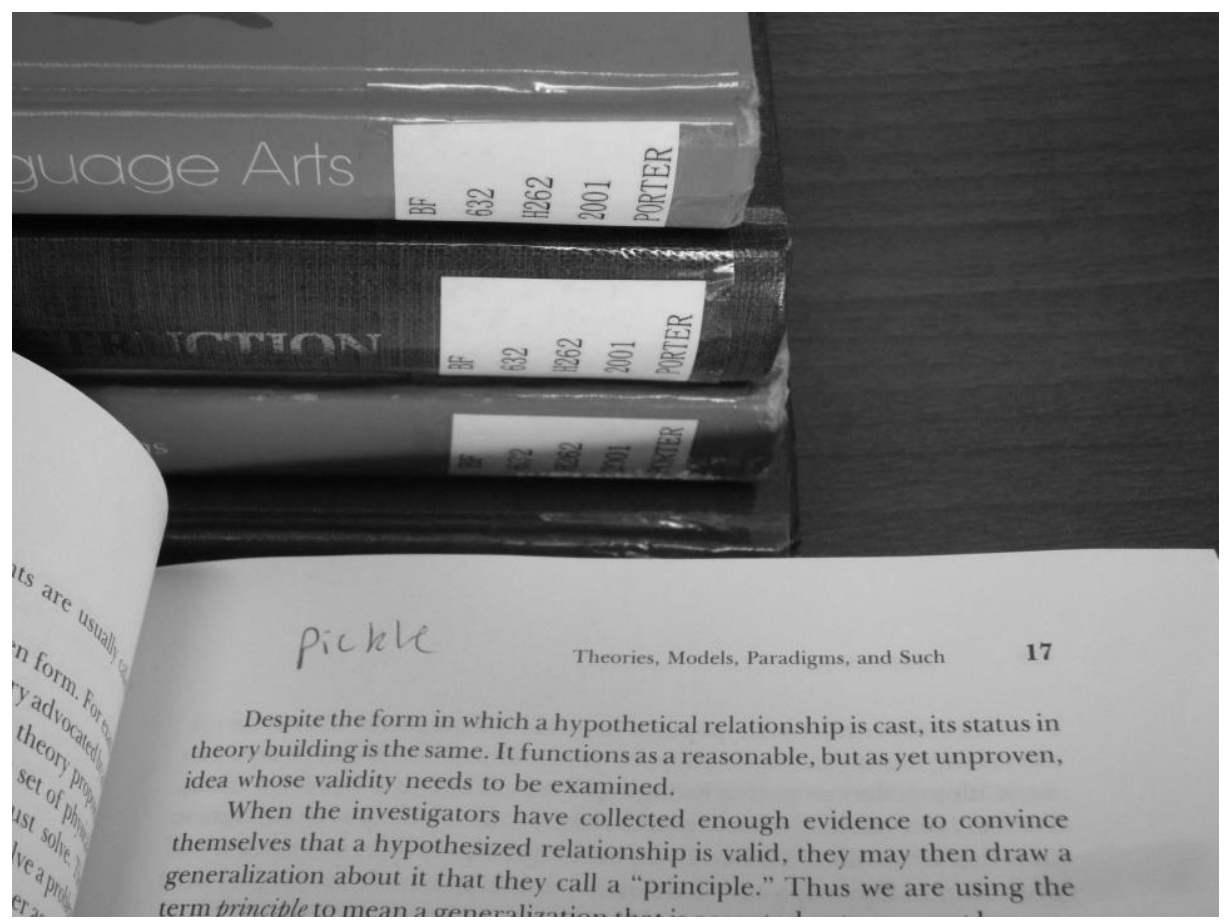


Figure 3. How comfortable an actor would feel making ethical decisions (i.e., choosing not to buy children alcohol, give a friend a prescription drug, download a movie illegally, or read a colleague's private messages) by perspective condition and whether unethical advice or no advice was given in Study 3.

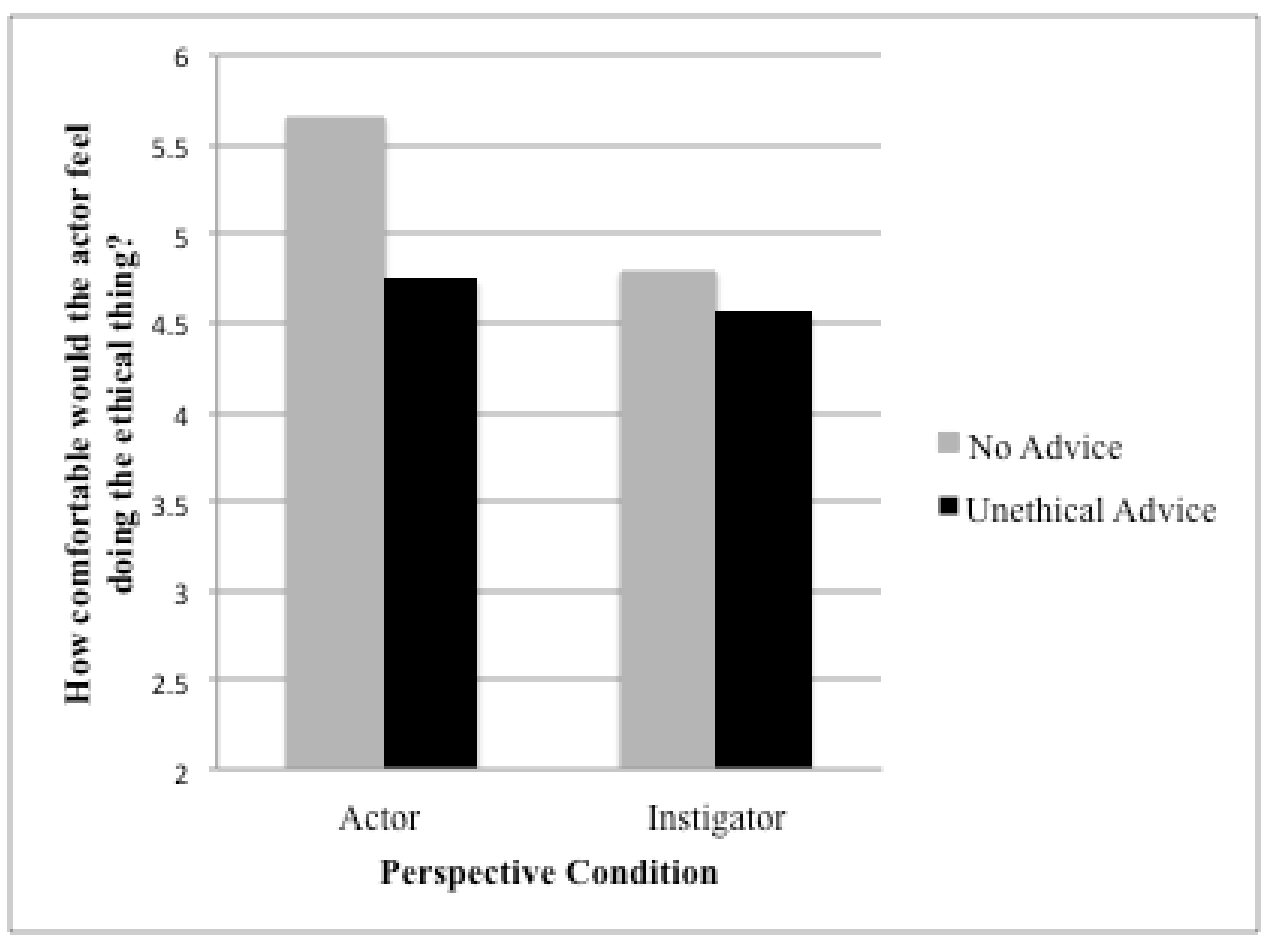


Figure 4. How comfortable an actor would feel making unethical decisions (i.e., calling in sick to go to a baseball game, taking company supplies home, freelancing for a corporate competitor, or expensing personal dinners) by perspective condition and whether unethical advice or ethical advice was given in Study 4.

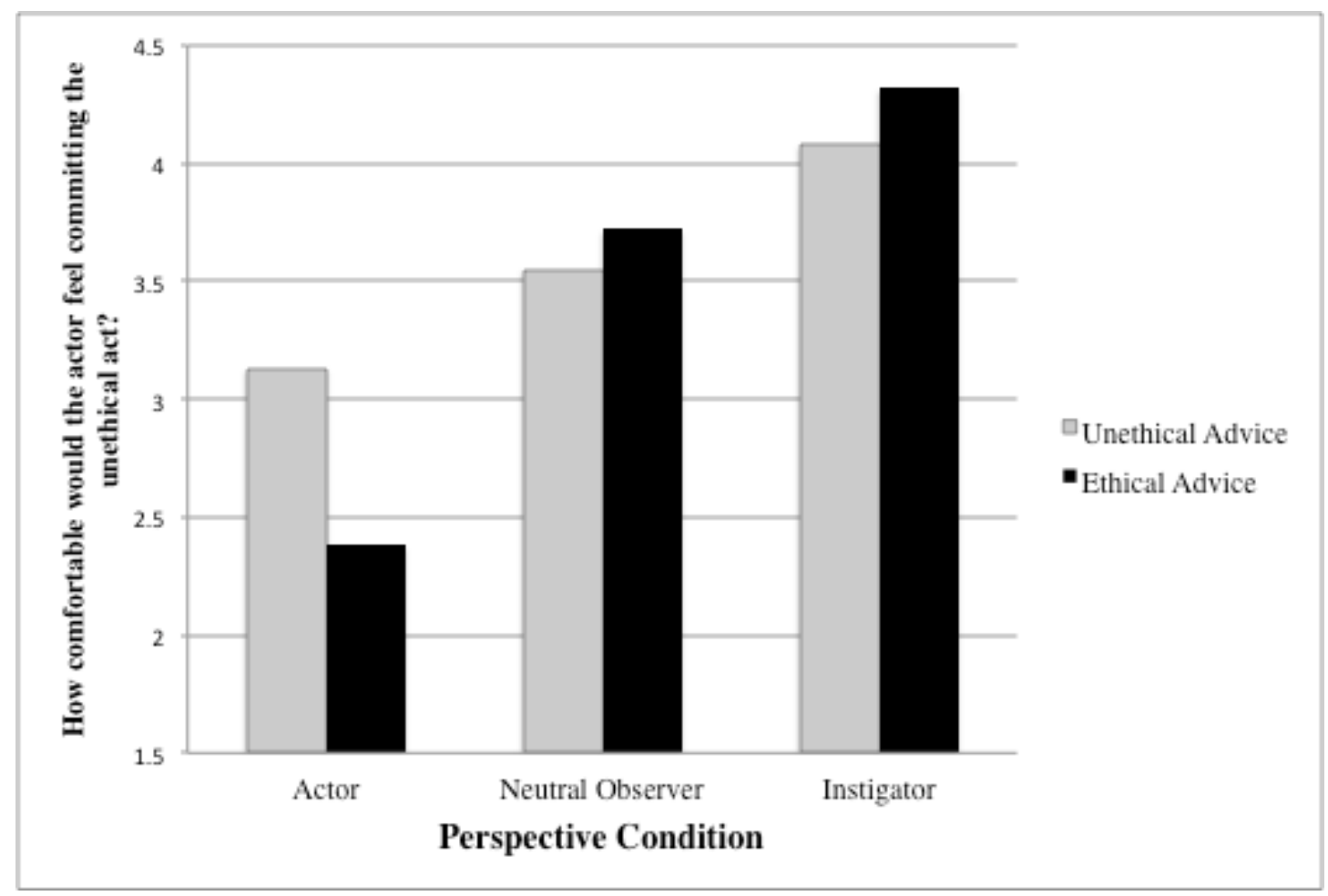


Underestimating our unethical influence 44

\section{Appendix A. Study 3 Scenarios by Perspective with Unethical Advice condition in}

\section{brackets.}

\begin{tabular}{|c|c|}
\hline CONDITION & SCENARIO \\
\hline & BUYING BEER FOR UNDERAGE KIDS \\
\hline $\begin{array}{l}\text { Actor } \\
\text { [Unethical } \\
\text { Suggestion] }\end{array}$ & $\begin{array}{l}\text { Imagine that you and a friend are running into the liquor store to buy some beer to bring to a party. A couple of kids who look } \\
\text { like they're in college are standing in the parking lot across from the liquor store. You park, get out of the car, and start walking } \\
\text { towards the liquor store. As you pass the college kids, one of them politely gets your attention, saying, "Excuse me? We really } \\
\text { hate that we have to ask people this, but we're } 20 \text {-years old -- almost } 21 \text {, I swear!-- and so we can't buy alcohol. If we give you } \\
\text { some money, would you mind picking up a 6-pack of beer for us?" [Your friend grins and says to you, "Let's help them } \\
\text { out."] }\end{array}$ \\
\hline \multirow[t]{2}{*}{$\begin{array}{l}\text { Instigator } \\
\text { [Unethical } \\
\text { Suggestion] }\end{array}$} & $\begin{array}{l}\text { Imagine that you and a friend are running into the liquor store to buy some beer to bring to a party. A couple of kids who look } \\
\text { like they're in college are standing in the parking lot across from the liquor store. You park, get out of the car, and start walking } \\
\text { towards the liquor store. As you pass the college kids, one of them politely gets your friend's attention, saying, "Excuse me? We } \\
\text { really hate that we have to ask people this, but we're 20-years old -- almost 21, I swear!-- and so we can't buy alcohol. If we } \\
\text { give you some money, would you mind picking up a 6-pack of beer for us?" [You grin and say to your friend, "Let's help } \\
\text { them out."] }\end{array}$ \\
\hline & GIVING A FRIEND PRESCRIPTION VALIUM \\
\hline $\begin{array}{l}\text { Actor } \\
\text { [Unethical } \\
\text { Suggestion] }\end{array}$ & $\begin{array}{l}\text { Imagine that you previously went through a rough period in your life during which you experienced anxiety and panic } \\
\text { attacks. To cope, you wound up getting a prescription for Valium, an anti-anxiety drug, from your doctor. However, you only } \\
\text { took a few pills, and now months later, you have a pretty full prescription bottle of Valium sitting in your medicine } \\
\text { cabinet. Recently, a good friend of yours has been going through her own rough time and has similarly been struggling with } \\
\text { anxiety attacks. Unfortunately, your friend doesn't have medical insurance and would have to pay a fee in order to see a doctor } \\
\text { or therapist. [A mutual friend of yours calls you up and asks if you would be willing to give a few of your Valium pills to } \\
\text { the friend who is having a rough time.] }\end{array}$ \\
\hline \multirow[t]{2}{*}{$\begin{array}{l}\text { Instigator } \\
\text { [Unethical } \\
\text { Suggestion] }\end{array}$} & $\begin{array}{l}\text { Imagine that a friend of yours previously went through a rough period in her life during which she experienced anxiety and } \\
\text { panic attacks. To cope, she wound up getting a prescription for Valium, an anti-anxiety drug, from her doctor. However, she } \\
\text { only took a few pills, and now months later, she has a pretty full prescription bottle of Valium sitting in her medicine } \\
\text { cabinet. Recently, a mutual friend of both of yours has been going through her own rough time and has similarly been } \\
\text { struggling with anxiety attacks. Unfortunately, this second friend doesn't have medical insurance and would have to pay a fee in } \\
\text { order to see a doctor or therapist. [You call your friend with the Valium up and ask if she would be willing to give a few of } \\
\text { her pills to your friend who is having a rough time.] }\end{array}$ \\
\hline & ILLEGALLY DOWNLOADING A MOVIE \\
\hline $\begin{array}{l}\text { Actor } \\
\text { [Unethical } \\
\text { Suggestion] }\end{array}$ & $\begin{array}{l}\text { Imagine that you and your roommate are having some friends over for a movie night. You are hosting because you have a } \\
\text { terrific projector that connects to your computer and a screen for projecting the movie. It makes your apartment feel like a } \\
\text { movie theater! You selected a movie in advance that everyone wanted to see. It's a movie that is available to rent through } \\
\text { iTunes and Netflix, but alternatively, you could just download it for free through a not-quite-legal file-sharing site. [Your } \\
\text { roommate has made it clear that he thinks it's stupid to pay a movie you can get for free.] }\end{array}$ \\
\hline \multirow[t]{2}{*}{$\begin{array}{l}\text { Instigator } \\
\text { [Unethical } \\
\text { Suggestion] }\end{array}$} & $\begin{array}{l}\text { Imagine that you and your roommate are having some friends over for a movie night. You are hosting because your roommate } \\
\text { has a terrific projector that connects to his computer and a screen for projecting the movie. It makes your apartment feel like a } \\
\text { movie theater! Your roommate selected a movie in advance that everyone wanted to see. It's a movie that is available to rent } \\
\text { through iTunes and Netflix, but alternatively, it can just be downloaded for free through a not-quite-legal file-sharing site. [You } \\
\text { have made it clear to your roommate that you think it's stupid to pay for a movie you can get for free.] }\end{array}$ \\
\hline & READING A COLLEAGUE'S PRIVATE MESSAGES \\
\hline $\begin{array}{l}\text { Actor } \\
\text { [Unethical } \\
\text { Suggestion] }\end{array}$ & $\begin{array}{l}\text { You and a colleague are working on a project at your desk. You realize the project would go faster if you both were able to } \\
\text { work on computers simultaneously. Unfortunately, your desks are far apart in the office and you both have immobile desktop } \\
\text { computers. Another colleague usually sits right next to you, but she is away from her desk for a couple of hours. You decide to } \\
\text { let your work partner use your computer while you move over to your mutual colleague's desk. You open up the internet } \\
\text { browser on your colleague's computer and notice that she is still logged into Facebook. Recently, there have been rumors about } \\
\text { this colleague's personal life that you could probably confirm or deny simply by peaking at her Facebook messages. [Your } \\
\text { work partner looks over your shoulder, grins, and says, "Nice. Check out her messages, and let's see if the rumors are } \\
\text { true."] }\end{array}$ \\
\hline $\begin{array}{l}\text { Instigator } \\
\text { [Unethical } \\
\text { Suggestion] }\end{array}$ & $\begin{array}{l}\text { You and a colleague are working on a project at his desk. You realize the project would go faster if you both were able to work } \\
\text { on computers simultaneously. Unfortunately, your desks are far apart in the office and you both have immobile desktop } \\
\text { computers. Another colleague usually sits right next to your work partner, but she is away from her desk for a couple of } \\
\text { hours. Your work partner decides to let you use his computer while he moves over to your mutual colleague's desk. He opens } \\
\text { up the internet browser on your colleague's computer and notices that she is still logged into Facebook. Recently, there have } \\
\text { been rumors about this colleague's personal life that you could probably confirm or deny simply by peaking at her Facebook } \\
\text { messages. [You look over your work partner's shoulder, grin, and say, "Nice. Check out her messages, and let's see if } \\
\text { the rumors are true."] }\end{array}$ \\
\hline
\end{tabular}


Underestimating our unethical influence 45

Appendix B. Study 4 Scenarios by Perspective with Unethical Advice/Ethical Advice

conditions in brackets.

\begin{tabular}{|c|c|}
\hline CONDITION & SCENARIO \\
\hline & $\begin{array}{l}\text { CALLING IN SICK TO GO TO A BASEBALL GAME } \\
\end{array}$ \\
\hline $\begin{array}{l}\text { Actor } \\
\text { [Unethical/ } \\
\text { Ethical } \\
\text { Suggestion] }\end{array}$ & $\begin{array}{l}\text { Imagine that you were just offered tickets to a baseball game that you really want to go to. The problem is that the game is tomorrow } \\
\text { afternoon, and it's too late to ask your boss to take the day off. While you're out having drinks with a co-worker after work, you tell } \\
\text { your co-worker that you're considering calling in sick the next day so you can go to the baseball game. Your co-worker says, ["Sure, If } \\
\text { it was me, I would totally do that."/"I don't know. If it was me, I probably wouldn't do that."] }\end{array}$ \\
\hline $\begin{array}{l}\text { Instigator } \\
\text { [Unethical/ } \\
\text { Ethical } \\
\text { Suggestion] }\end{array}$ & $\begin{array}{l}\text { Imagine that one of your co-workers was just offered tickets to a baseball game that he or she really wants to go to. The problem is that } \\
\text { the game is tomorrow afternoon, and it's too late for your co-worker to ask his or her boss to take the day off. While you're out having } \\
\text { drinks with this person after work, he or she tells you that he or she is considering calling in sick the next day to go to the baseball } \\
\text { game. You say, ["Sure, If it was me, I would totally do that."/"I don't know. If it was me, I probably wouldn't do that."] }\end{array}$ \\
\hline \multirow[t]{2}{*}{$\begin{array}{l}\text { Neutral } \\
\text { Observer } \\
\text { [Unethical/ } \\
\text { Ethical } \\
\text { Suggestion] }\end{array}$} & $\begin{array}{l}\text { Imagine that someone was just offered tickets to a baseball game that he or she really wants to go to. The problem is that the game is } \\
\text { the following afternoon, and it's too late for this individual to ask his or her boss to take the day off. While this person is out having } \\
\text { drinks with a co-worker after work, he or she tells the co-worker that he or she is considering calling in sick the next day to go to the } \\
\text { baseball game. The person's co-worker says, ["Sure, If it was me, I would totally do that."/"I don't know. If it was me, I probably } \\
\text { wouldn't do that."] }\end{array}$ \\
\hline & $\begin{array}{l}\text { TAKING OFFICE SUPPLIES HOME FOR PERSONAL USE } \\
\end{array}$ \\
\hline $\begin{array}{l}\text { Actor } \\
\text { [Unethical/ } \\
\text { Ethical } \\
\text { Suggestion] }\end{array}$ & $\begin{array}{l}\text { Imagine that you are out of printer paper at home. The supply closest at work is full of reams of paper, but employees are not supposed } \\
\text { to use office supplies for personal purposes. As you are taking a look at what is in the supply closet, one of your co-workers walks in. } \\
\text { You ask what your co-worker thinks about the possibility of your taking some printer paper home for yourself. Your co-worker says, } \\
\text { ["I think that would be fine."/"I don't think it's such a good idea."] }\end{array}$ \\
\hline $\begin{array}{l}\text { Instigator } \\
\text { [Unethical/ } \\
\text { Ethical } \\
\text { Suggestion] }\end{array}$ & $\begin{array}{l}\text { Imagine that your co-worker is out of printer paper at home. The supply closest at work is full of reams of paper, but employees are not } \\
\text { supposed to use office supplies for personal purposes. As this person is taking a look at what is in the supply closet, you walk in. Your } \\
\text { co-worker asks you what you think about the possibility of him or her taking some printer paper home for personal use. You say, ["I } \\
\text { think that would be fine."/"I don't think it's such a good idea."] }\end{array}$ \\
\hline \multirow[t]{2}{*}{$\begin{array}{l}\text { Neutral } \\
\text { Observer } \\
\text { [Unethical/ } \\
\text { Ethical } \\
\text { Suggestion] }\end{array}$} & $\begin{array}{l}\text { Imagine that someone is out of printer paper at home. This person's supply closest at work is full of reams of paper, but employees are } \\
\text { not supposed to use office supplies for personal purposes. As this individual takes a look at what is in the supply closet, a co-worker } \\
\text { walks in. The person asks his or her co-worker what the co-worker thinks about the possibility of taking some printer paper home for } \\
\text { personal use. The co-worker says, ["I think that would be fine."/"I don't think it's such a good idea."] }\end{array}$ \\
\hline & $\begin{array}{l}\text { FREELANCING FOR A CORPORATE COMPETITOR } \\
\end{array}$ \\
\hline $\begin{array}{l}\text { Actor } \\
\text { [Unethical/ } \\
\text { Ethical } \\
\text { Suggestion] }\end{array}$ & $\begin{array}{l}\text { Imagine that you are working at a corporation with a clear policy against employees working for potential competitors on the } \\
\text { side. However, your friend just began running a start-up that may one day pose a competition to your firm, and this friend has asked } \\
\text { you as a favor whether you would be willing to consult for the start-up for a few hours a week. You mention this opportunity to one of } \\
\text { your colleagues at work who says, ["If you want my advice, I'd say just go ahead and do it."/"If you want my advice, I'd say you } \\
\text { probably shouldn't do it."] }\end{array}$ \\
\hline $\begin{array}{l}\text { Instigator } \\
\text { [Unethical/ } \\
\text { Ethical } \\
\text { Suggestion] }\end{array}$ & $\begin{array}{l}\text { Imagine that you are working at a corporation with a clear policy against employees working for potential competitors on the } \\
\text { side. However, your co-worker's friend just began running a start-up that may one day pose a competition to your firm, and this } \\
\text { person's friend has asked as a favor whether your co-worker would be willing to consult for the start-up for a few hours a week. When } \\
\text { your co-worker mentions this opportunity to you, you say, ["If you want my advice, I'd say just go ahead and do it."/"If you want } \\
\text { my advice, I'd say you probably shouldn't do it."] }\end{array}$ \\
\hline \multirow[t]{2}{*}{$\begin{array}{l}\text { Neutral } \\
\text { Observer } \\
\text { [Unethical/ } \\
\text { Ethical } \\
\text { Suggestion] }\end{array}$} & $\begin{array}{l}\text { Imagine a person who is working at a corporation with a clear policy against employees working for potential competitors on the } \\
\text { side. However, this person's friend just began running a start-up that may one day pose a competition to his or her firm, and this } \\
\text { person's friend has asked as a favor whether this person would be willing to consult for the start-up for a few hours a week. This } \\
\text { individual is considering whether he or she should take this opportunity on the side. He or she mentions this opportunity to one of his or } \\
\text { her colleagues at work who says, ["If you want my advice, I'd say just go ahead and do it."/"If you want my advice, I'd say you } \\
\text { probably shouldn't do it."] }\end{array}$ \\
\hline & EXPENSING PERSONAL DINNERS \\
\hline $\begin{array}{l}\text { Actor } \\
\text { [Unethical/ } \\
\text { Ethical } \\
\text { Suggestion] }\end{array}$ & $\begin{array}{l}\text { Imagine that you are filling out your expense report from a conference you just attended. Since the conference was in Hawaii, you } \\
\text { brought your spouse along to make it a vacation as well. You aren't supposed to expense non-business-related dinners, but you are } \\
\text { considering putting just a couple of the romantic dinners you spent with your spouse down on your expense form. No one would be } \\
\text { able to tell. You run the idea by a close friend who says, ["Why not? That seems okay to me."/"I don't know. That seems pretty } \\
\text { wrong to me."] }\end{array}$ \\
\hline $\begin{array}{l}\text { Instigator } \\
\text { [Unethical/ } \\
\text { Ethical } \\
\text { Suggestion] }\end{array}$ & $\begin{array}{l}\text { Imagine that a close friend of yours is filling out his or her expense report from a conference he or she just attended. Since the } \\
\text { conference was in Hawaii, this person brought his or her spouse along to make it a vacation as well. Your friend isn't supposed to } \\
\text { expense non-business-related dinners, but he or she is considering putting just a couple of the romantic dinners he or she spent with his } \\
\text { or her spouse down on the expense form. No one would be able to tell. Your friend runs this idea by you, and you say, ["Why not? } \\
\text { That seems okay to me."/"I don't know. That seems pretty wrong to me."] }\end{array}$ \\
\hline $\begin{array}{l}\text { Neutral } \\
\text { Observer } \\
\text { [Unethical/ } \\
\text { Ethical } \\
\text { Suggestion] }\end{array}$ & $\begin{array}{l}\text { Imagine someone is filling out his or her expense report from a conference this person just attended. Since the conference was in } \\
\text { Hawaii, this person brought his or her spouse along to make it a vacation as well. He or she isn't supposed to expense non-business- } \\
\text { related dinners, but is considering putting just a couple of the romantic dinners spent with his or her spouse down on the expense } \\
\text { form. No one would be able to tell. The person runs the idea by a close friend who says, ["Why not? That seems okay to me."/"I } \\
\text { don't know. That seems pretty wrong to me."] }\end{array}$ \\
\hline
\end{tabular}

